\section{Contributors}

Matthew Burkes

mattburkes@doctors.net.uk

Mohammed Saqib Anwa

saq64@doctors.org.uk

\section{Qashif Anwar}

qashifanwar@doctors.org.uk

\section{Matthew Burkes}

mattburkes@doctors.net.uk

\section{Jeff Clark}

jeff.clark@gp-L81033.nhs.uk

Jan De Maeseneer

jan.demaeseneer@ugent.be

\section{Mike Fitzpatrick}

fitz@easynet.co.uk

Charles Foster

charles.foster@outertemple.com

\section{Sally Hope}

SHope@doctors.org.uk

\section{Tony Hope}

tony.hope@ethox.ox.ac.uk

Helen Lester

Helen.Lester@manchester.ac.uk

Farhan Munawar

farhanmunwar@doctors.org.uk

Mariet Paes

m.paes@prvmz.nl

Peter D Toon

petertoon@aol.com

Graham Watt

gcmw1j@clinmed.gla.ac.uk

\title{
A stitch in time
}

When I was in the first year of senior school, my friend's brother was generally regarded as something of a rising star. He had just gone to university where he got a first and then moved on to his PhD. Things started to go wrong in the second year. He came from a devoutly religious family so when his long-standing beliefs became more pronounced, it was not seen as anything particularly out of the ordinary. But within a year he had dropped out of university, spent a long time not getting medical help and was finally, far too late, diagnosed with schizophrenia. I still feel a palpable sense of loss for what his life might have been.

His story is not an isolated one. Psychosis affects over three people in every 100 , making it about as common as insulindependent diabetes. A few years ago, as a GP in a medical unit for people who were homeless, I used to ask new patients to tell me their story, not of their coughs and bad feet, but of why they had turned up at Summerhill instead of a 'normal' surgery. I heard tales of divorce, lost jobs, and too much alcohol. Within that very particular largely rough-sleeping and hostel-dwelling population, about $30 \%$ of people also described 'breakdowns' as teenagers from which they had never really recovered. Many of these middle-aged men (and some women) had, in all probability, had an episode of psychosis that was unrecognised or untreated, and fallen out of the system.

It is, of course, hard to make a diagnosis of psychosis in primary care. In spite of the stereotypes of mental illness, people don't tend to present with full-blown auditory hallucinations but with subtle and uncertain signs of social withdrawal and a gradual intellectual deterioration. Families become uneasy that something might be wrong, but then most parents of a teenager will tell you stories of bedrooms becoming bear caves with yesterday's supper plate hidden under last week's socks. Judging when normal becomes a cause for concern is an art form as much as a science. These difficulties with diagnosis mean that until very recently, many young people with an incipient psychosis spent between 1 and 2 years with slowly worsening symptoms before they received effective treatment. ${ }^{1}$

Things are, however, beginning to improve. In England and many parts of the rest of the UK, there are now bespoke 'Early Intervention Services' for young people with a first episode of psychosis. Being diagnosed earlier and referred to a service that knows how to treat you makes a real difference. You are more likely to make a quicker recovery, less likely to relapse and also less likely to commit suicide. ${ }^{2}$ The RCGP has been active in this area too. College members have written joint guidance with the Royal College of Psychiatrists on early detection of psychosis in young people, ${ }^{3}$ and knowledge of early detection, referral, and the importance of family support are now all part of the GP Curriculum. There is still much work to be done though. We have not yet, I think, as a profession, really come to terms with the fact that many young people are now exiting Early Intervention Services with risk factors that increase their chances of highly treatable cardiovascular disease. ${ }^{3}$ We need to think ahead with them, intervening early rather than waiting for physical health problems to present.

In a sense, primary care has been given a series of challenges. We are the most frequently consulted profession when a young person is developing a psychosis. There's also some recent evidence that with minimal but targeted education, we refer earlier and more appropriately. ${ }^{4}$ We are the part of the health service that remains constant during the illness and after discharge. This may all be too late for our oldest patients with established psychosis whose paths were changed forever by the diagnosis. But perhaps, the next time we see a withdrawn young person or talk to their worried mum or dad and suspect the diagnosis, we may be able to be both a little more helpful and hopeful.

\section{REFERENCES}

1. Norman R, Malla AK. Duration of untreated psychosis: a critical examination of the concept and its importance. Psychol Med 2001; 31(3): 381-400.

2. Addington J. The promise of early intervention. Early Interv Psychiatry 2007; 1(4): 294-307.

3. Primary Care Guidance: Early intervention in psychosis - Looking after bodies as well as minds. http://www.gmw.nhs.uk/sites/earlyinterventiontraining /physical_health_guidance.pdf (accessed 26 Nov 2009).

4. Power P, Iacoponi E, Reynolds N, et al. The Lambeth Early Onset crisis assessment team study: general practitioner education and access to an early detection team in first episode psychosis. Br J Psychiatr 2007;191: s133-139. doi: 10.1192/bjp.191.51.s133.

DOI: 10.3399/bjgp10X482257 